\title{
Effect of Tempering Temperature on the Corrosion Behavior of R5 Steel in Artificial Seawater
}

\author{
Shiyang Zhang ${ }^{1}$, Xiaoying Cheng ${ }^{1,2, *}$, Lingchao $\mathrm{Su}^{1}$, Chaowei Jiang ${ }^{1}$ \\ ${ }^{1}$ Institute of Materials, Shanghai University, Shanghai 200072, China \\ ${ }^{2}$ Laboratory for Microstructures, Shanghai University, Shanghai 200444, China \\ *E-mail: chengxyshu@126.com
}

doi: $10.20964 / 2017.03 .69$

Received: 4 January 2017 / Accepted: 30 January 2017 / Published: 12 February 2017

\begin{abstract}
The effect of tempering temperature $\left(560{ }^{\circ} \mathrm{C}, 600{ }^{\circ} \mathrm{C}\right.$ and $640{ }^{\circ} \mathrm{C}$, denoted as T560, T600 and T640, respectively) on the corrosion behavior of $\mathrm{R} 5$ steel (a kind of mooring chain steel) in artificial seawater was studied by immersion tests and electrochemical measurements combined with scanning electron microscopy (SEM). X-ray diffraction (XRD) was conducted to analyze the corrosion products. The results indicated that the corrosion resistance of the steel was increased with elevating tempering temperature. Steel T640 with higher tempering temperature exhibited excellent corrosion resistance with lower corrosion current density, a less weight loss and bigger impedance modulus than steels T560 and T600. The distinction of corrosion resistance can be attributed to the different grain size and carbide density in the microstructure.
\end{abstract}

Keywords: Mooring chain steel; Tempering temperature; Corrosion resistance; Electrochemical measurement

\section{$\underline{\text { FULL TEXT }}$}

(C) 2017 The Authors. Published by ESG (www.electrochemsci.org). This article is an open access article distributed under the terms and conditions of the Creative Commons Attribution license (http://creativecommons.org/licenses/by/4.0/). 